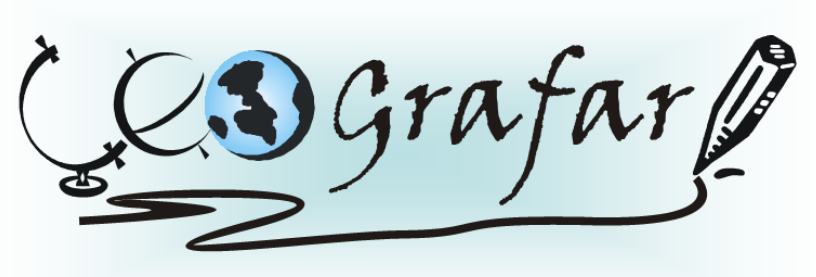

Revista Eletrônica do Programa de Pós-Graduação em Geografia - UFPR

\title{
OS CASSACOS MIGRANTES DE TAMBOARA - PR: REFLEXOS DA MODERNIZAÇÃO CONSERVADORA
}

\section{THE MIGRANTS "CASSACOS" OF TAMBOARA: REFLECTIONS OF CONSERVATIVE MODERNIZATION}

\section{(Recebido em 15-01-2017; Aceito em: 26-01-2017)}

Vitor Hugo Ribeiro

Doutor em Geografia pelo Programa de Pós-Graduação em Geografia da Universidade Estadual de Maringá e integrante do Núcleo de Estudos de Mobilidade e Mobilização. vitor.vhr@hotmail.com

\section{Resumo}

Este artigo, resultado de um trabalho de doutorado em Geografia, objetivou estudar a mobilidade de trabalhadores e trabalhadoras rurais migrantes do município de Tamboara - PR, levando-se em consideração algumas características sociais, bem como as motivações desse fluxo populacional. Averiguou-se, por meio de trabalho de campo, que a exclusão social porque passam esses trabalhadores é reflexo da modernização conservadora e do processo de reestruturação produtiva do capital em nosso país. Tais elementos foram desencadeadores de uma força de trabalho rural de baixa escolarização e excludente do mercado de trabalho formal que tem adquirido, por meio dos fluxos migratórios, oportunidades de conquistar melhores condições de vida e anseios.

Palavras-chave: Tamboara - PR; Lavoura canavieira; Fluxo populacional.

\section{Abstract}

This article, the result of a PhD work in geography, was aimed at studying the mobility of migrant rural labors in the municipality of Tamboara, considering some social characteristics as well as the motivations of this population flow. It has been found through fieldwork that the social exclusion of these workers is a reflection of the conservative modernization and the process of productive restructuring of capital in our country. These elements have triggered a rural labor force with low schooling and excluding the formal labor market, which has acquired, through migratory flows, the opportunities to achieve better life conditions and desires.

Keywords: Tamboara; Sugar cane plantation; Population flow. 


\section{Introdução}

A mobilidade da força de trabalho está concomitantemente articulada à história do homem. No entanto, ela nunca aconteceu de maneira tão exacerbada quanto após a mundialização econômica (IANNI, 1997), sobretudo no processo da modernização conservadora. Em tratando-se do território brasileiro, a formação histórica do Brasil contemporâneo, de acordo com Prado Jr (1970), se deu, quase que exclusivamente, com as correntes de povoamento motivadas pela economia extrativista num primeiro momento e, posteriormente, com a grande lavoura açucareira, com a pecuária e a mineração e mais tarde o café, dentre outros, como a indústria, as artes e o comércio, além das vias de comunicação e transporte. Essas atividades influenciaram a vida social da população brasileira, bem como os setores administrativos, artísticos e políticos.

No âmbito dessas atividades econômicas, é impossível deixar de lembrar da mão de obra nordestina e os constantes fluxos de mobilidade às regiões que desenvolviam as respectivas atividades econômicas. Tamanha foi a importância da força de trabalho daquela região, sobretudo aquela advinda do meio rural, que um saudoso folclorista nordestino, Rodrigues de Carvalho, documentou na poesia popular o vocábulo "cassaco", sinônimo de trabalhador do campo, uma adaptação de "cossaco", população camponesa russa que ajudou na formação daquele país:

\section{Os cassacos da Usina Só comem carne de boi; Trabalham a 1500,

Na poesia popular, "cassaco" refere-se ao baixo nível de remuneração e opressão econômica por parte do poderio dos "senhores de engenho" que durante muito tempo recebeu o trabalhador rural nordestino ingressado na atividade canavieira. Pelo fato de os trabalhadores nordestinos terem migrado ao longo de todo o território brasileiro desde o Período Colonial, contribuindo diretamente com a formação do Brasil contemporâneo, não há dúvida, conforme Ribeiro (1977), de que os nordestinos são os cossacos do Brasil.

Se no passado colonial a força de trabalho nordestina foi importante para a formação e desenvolvimento do Brasil, atualmente ela ainda é fundamental para mover certas atividades, especialmente do ramo sucroalcooleiro localizado em regiões que ainda dependem do corte manual da cana-de-açúcar, a exemplo do Noroeste Paranaense. No entanto, tais atividades mobilizam, como poderá perceber nesta pesquisa, trabalhadores errantes de baixa escolarização e que vivem num meio 
de origem que denota certas peculiaridades e precariedades socioespaciais, cuja busca por melhores condições de vida se dá por meio da mobilidade forçada.

Outrora os cassacos eram oprimidos pelos senhores dos engenhos e, atualmente, os são pela modernização conservadora. Esta ocasionou a emergência de um novo trabalhador rural, desqualificado em diversos setores que exigem certa intelectualização, desterritorializado, precarizado e expropriado dos meios de produção, destituído dos direitos sociais e trabalhistas, e a sua busca por melhores condições de vida e trabalho se dá por meio dos movimentos migratórios, migrando de um lugar para outro, por diferentes cidades e regiões, criando e recriando o seu mapa do mundo do trabalho (IANNI, 1978).

Esses elementos contraditórios estão presentes na população migrante do município de Tamboara - PR, sobretudo naqueles de origem nordestina que praticam atividades de plantio e corte da cana-de-açúcar. Esses trabalhadores são motivados a esse deslocamento devido às consequências e possibilidades impostas por esse momento do capitalismo global que resultou em abundantes modificações, muitas delas radicais e contraditórias, no mundo do trabalho, nos hábitos de consumo da população, nas configurações geográficas, nas práticas e poderes do Estado, dentre outras (HARVEY, 1993).

Portanto, pretende-se neste trabalho apresentar resultados do estudo da mobilidade de trabalhadores rurais oriundos do nordeste brasileiro que vêm todos os anos ao Paraná para trabalhar no corte da cana-de-açúcar. A área de estudo compreende o município de Tamboara localizado na Mesorregião Noroeste Paranaense e, a partir de investigações de campo, averiguou-se, por meio de questionários e entrevistas, o fluxo e o perfil de migrantes cortadores de cana-de-açúcar, bem como as motivações que os fizeram migrar ao Paraná.

Estima-se que, dos anos 2000 a 2014, aproximadamente trezentos trabalhadores de origem nordestina migraram a Tamboara, motivados pelos serviços ofertados pela Usina COOPCANA do município vizinho, São Carlos do Ivaí. Para tanto, os questionários foram aplicados para cinquenta trabalhadores, concebendo em torno de $16 \%$ da realidade, e levou-se em consideração as seguintes variáveis adaptadas de Lima (2011): o período de migração, a origem, a etnia, a escolaridade e a atividade profissional, a idade, o gênero e o estado civil, a situação de moradia, bem como as motivações que os fizeram migrar ao Paraná. Tais informações foram importantes para 0 reconhecimento da realidade social desses trabalhadores.

Atrelada a essa compilação de dados, também foi importante as informações secundárias a partir dos institutos de pesquisas, como o Instituto Brasileiro de Geografia e Estatística (IBGE) e 0 Instituto de Pesquisa e Estratégia Econômica do Ceará (IPECE), para adquirir informações precisas 
acerca dos municípios de origem e destino que vêm se reproduzindo em função desse movimento populacional.

\section{Apontamentos sobre o município de Tamboara - Pr}

O município de Tamboara localiza-se na Mesorregião Noroeste Paranaense do Estado do Paraná (Figura 01), localidade coberta por arenitos da Formação Caiuá, onde originaram solos arenosos e predominam as formas de relevo suavemente onduladas com topos aplainados (RIBEIRO, 2016), propícias às atividades agrícolas. Porém, estes solos dificultam bastante a introdução de culturas consideradas modernas como a soja, dentre outras. A origem da cidade de Tamboara remonta a economia cafeeira, instaurada em 1947 pela Empresa Colonizadora Engenheiro Beltrão. Tamboara foi desmembrada do município de Paranavaí em 1954, passando, então, a ter a sua administração própria.

Figura 01: Localização geográfica de Tamboara-PR.

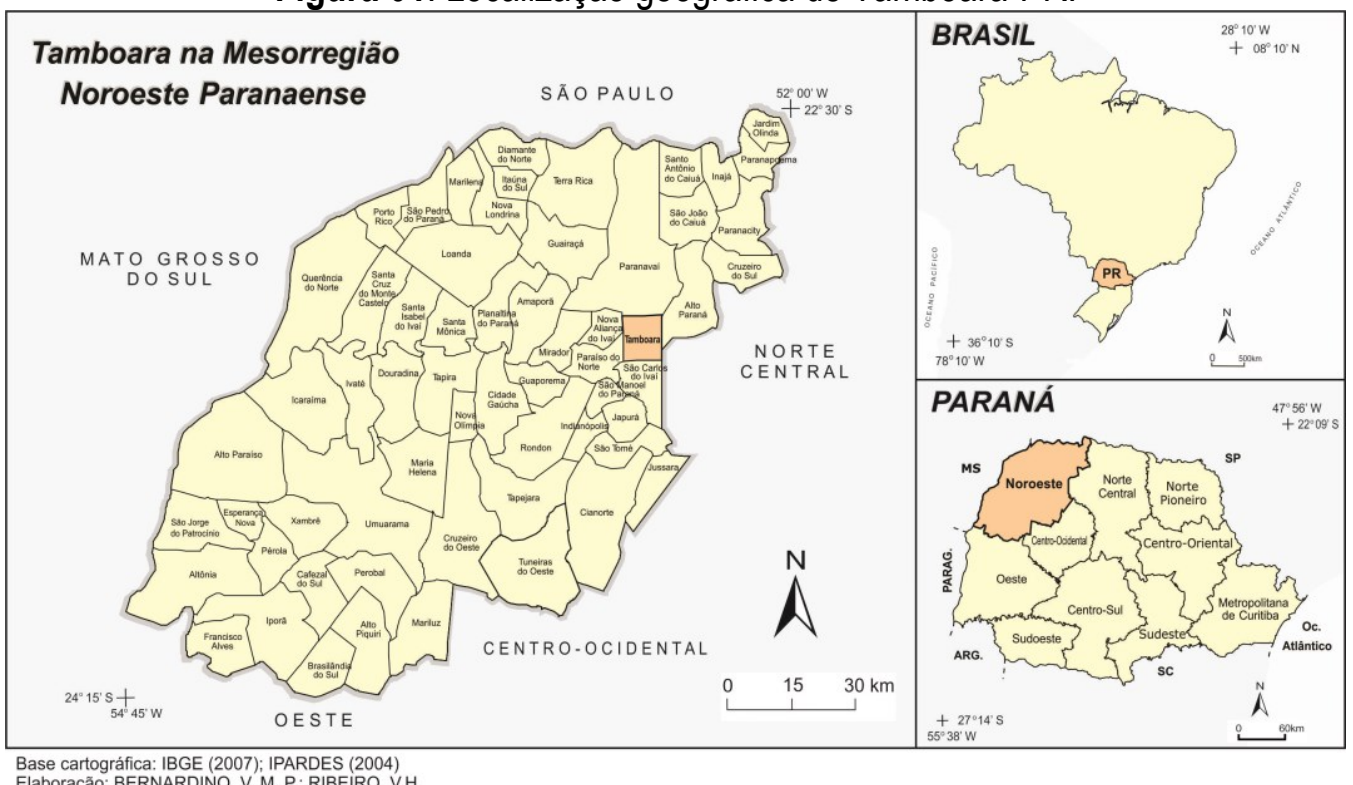

O município em questão reflete a história do Norte Paranaense, tendo o seu auge econômico na época da atividade cafeeira, sendo que, posteriormente, com a mecanização agrícola, conheceu uma ampla evasão populacional. No auge do café, principalmente nos anos 1960/70, a população de Tamboara era em torno de 12.000 habitantes (RIBEIRO, et al, 2013), e a cidade possuía uma economia mais dinâmica, sendo, por exemplo, contemplada com um cinema, desativado mais tarde decorrente da crise cafeeira, que gerou uma considerada emigração da população local.

A economia local é movida pela agricultura, tendo a cana-de-açúcar, seguida pela mandioca e milho, os principais cultivos. A pecuária também é desenvolvida no município, porém, desde os anos 
1987, a atividade se encontra em declínio. Naquele ano, as pastagens ocupavam $81,27 \%$ do uso do solo do município, mas, em 2011, representavam 44,37\%, uma redução de aproximadamente $45 \%$. A agricultura detinha aproximadamente $17,29 \%$ do uso do solo no ano de 1987, e em 2011 esta se expandiu para 50,09\%. Esse aumento foi decorrente das novas atividades que se intensificaram no meio rural, como a mandioca e, principalmente, a cana-de-açúcar (RIBEIRO et al, 2013).

No início deste século, a população do município de Tamboara foi mensurada em 4.664 habitantes, de acordo com IBGE (2010). Destes, 668 viviam no meio rural e 3.996 no meio urbano. A População Economicamente Ativa do município compreendeu 2.420 trabalhadores, e a maior parte dessa força de trabalho, no que abrange $68 \%$, trabalha no setor de serviços. No setor industrial, estima-se que um pouco mais de 6\% da PEA está empregada, e o restante insere-se nas atividades advindas da agricultura (IPARDES, 2013).

A partir dos anos 2000 o município vem recebendo um número significativo de trabalhadores nordestinos. Acredita-se que, entre os anos 2000 a 2014 aproximadamente trezentas pessoas migraram a Tamboara motivadas pelas atividades agrícolas, sobretudo voltadas ao setor sucroalcooleiro do município de São Carlos do Ivaí. Nesta região, a COOPCANA foi fundada nos finais da década de 1970, motivada pelas políticas do Programa Nacional do Álcool (PROALCOOL) e, atualmente, a cooperativa possui 128 associados que cultivam e arcam com os custos da lavoura de cana-de-açúcar (RIBEIRO, 2016).

No ano de 2012, a cooperativa plantou aproximadamente 3.500 alqueires de cana-de- açúcar e moeu 3.250.000 toneladas, produzindo 140.000 toneladas de açúcar e 175 milhões de litros de etanol (RIBEIRO, 2016). A dinâmica da COOPCANA extrapola os limites municipais de São Carlos do Ivaí, de modo que os associados da cooperativa são oriundos de outros municípios, como Paranavaí, Alto Paraná, Tamboara, São Carlos do Ivaí, Nova Aliança do Ivaí, Paraíso do Norte, Mirador e Amaporã. São localidades que estão no raio de atuação da usina, entre 25 a 30 quilômetros.

As atividades econômicas são fenômenos cruciais que polarizam e desencadeiam a mobilidade centrada no trabalho. De acordo com Perroux (1967), uma economia local gera uma certa autonomia e crescimento em uma determinada região, proporcionando funções significativas à demanda populacional, tanto interna quanto externa à região. Embora o município de Tamboara não seja um polo econômico da mesorregião Noroeste Paranaense, a localidade vem recebendo um fluxo importante de população na última década para ser inserida nas atividades rurais da Usina COOPCANA, sobretudo no corte da cana-de-açúcar, na mesma lógica do desenvolvimento industrial local. 
Isso acontece porque os segmentos agroindustriais do ramo sucroalcooleiro na Mesorregião Noroeste Paranaense funcionam como "economias de aglomeração" nos moldes de Perroux (1967), no sentido de, por meio de suas empresas (usinas ou destilarias), promoverem uma atração populacional em razão da diversidade de bens de produção que proporcionam diferentes ofertas para o mercado de trabalho.

Essas empresas promovem a circulação dos fluxos populacionais e monetários na economia regional, proporcionando efeitos diretos nessas cidades. 0 crescimento populacional vem aumentando, principalmente com a atração da força de trabalho, que acaba contribuindo com o desenvolvimento local. Esses segmentos também são importantes para manter a população em municípios demograficamente pequenos, como retratado em Ribeiro (2013), diminuindo a evasão populacional para as localidades mais dinâmicas do Noroeste Paranaense, como Cianorte, Paranavaí e Umuarama. Em contrapartida, tem-se a problemática em torno da atividade canavieira, especialmente no que tange à expansão da gramínea sob áreas produtoras de alimentos. Produtores familiares, por exemplo, deixam de produzir para arrendar as terras à usina, fragilizando o circuito alimentar local.

No município de Tamboara não existe alojamento para os trabalhadores migrantes e os contratos de trabalho são efetivos, diferentes de outras localidades, tais como Cidade Gaúcha, que também recebe trabalhadores nordestinos, porém sua relação de trabalho se dá por meio de contratos temporários e essa força de trabalho permanece, durante a safra, em alojamento localizado na zona urbana. A migração que se assiste em Tamboara na última década percebe-se permanente. A maioria dos trabalhadores migraram, adquiriram moradia ou alugaram-na e ficaram na cidade. Muitos, como pode-se notar na sequência, vieram acompanhados de parentes ou amigos.

Essa migração definitiva vai produzindo e reproduzindo o espaço geográfico de Tamboara por meio do trabalho e do consumo, pois, esses migrantes, despendem quase que exclusivamente sua renda na localidade em questão. Se Ghizzo (2012) sinalizou a importância do consumo no processo de produção do espaço geográfico do aglomerado urbano de Maringá, em Tamboara também assistese esse processo, embora 0 município seja demograficamente pequeno. A Figura 02 apresenta a expansão do espaço urbano em um bairro novo que vem sendo produzido por migrantes, sobretudo nordestinos, que trabalham no corte da cana-de-açúcar e na mandiocultura. 
Figura 02: Expansão do espaço urbano de Tamboara fruto do processo migratório

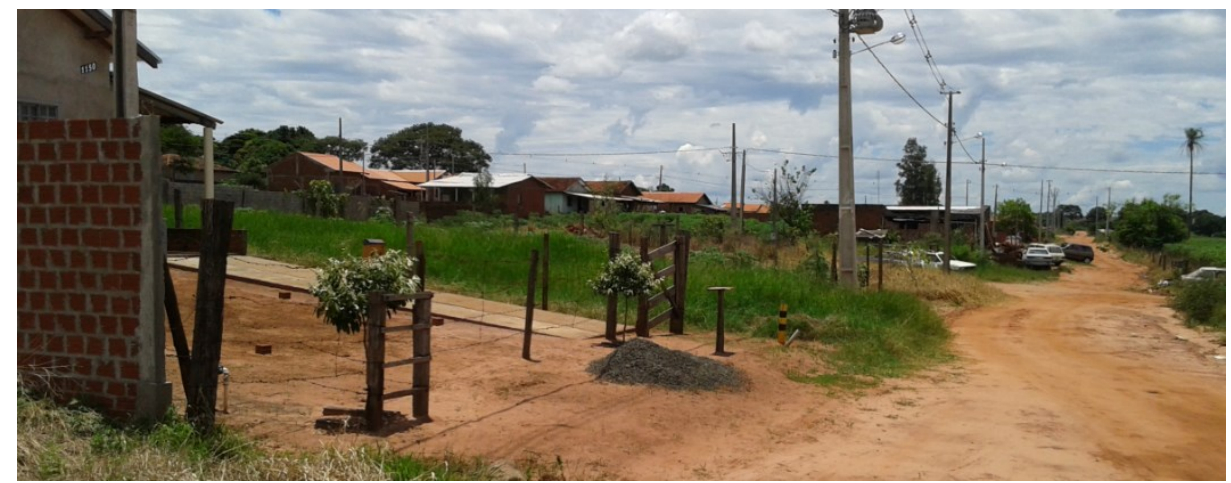

Fonte: RIBEIRO, 2016.

No que tange a questão urbana, percebe-se que a localidade necessita de maiores investimentos em serviços públicos de infraestrutura, tais como ruas asfaltadas, moradias, saneamento básico, dentre outros. Cabe, sobretudo ao Estado, garantir a melhoria deste e outros municípios que vêm assistindo um a aumento populacional graças às políticas energéticas e a consolidação do parque sucroalcooleiro no Noroeste Paranaense, mesorregião composta quase que exclusivamente por municípios demograficamente pequenos.

Essa problemática é resultado das discrepâncias econômicas que vêm refletindo no núcleo urbano de Tamboara ao longo das últimas décadas. Se por um lado a cidade apresenta a região central bem estruturada, por outro, apresenta também suas contradições socioespaciais (Figura 03). A cidade possui um centro, local de encontro e de atratividade populacional, e também uma área periférica para a população de baixa renda, desprovida de asfalto e rede de esgoto, dentre outros. As áreas periféricas são destinadas, quase que preferencialmente, para a população migrante que chegou à cidade nos últimos vinte anos.

Figura 03: Centro e periferia do núcleo urbano de Tamboara

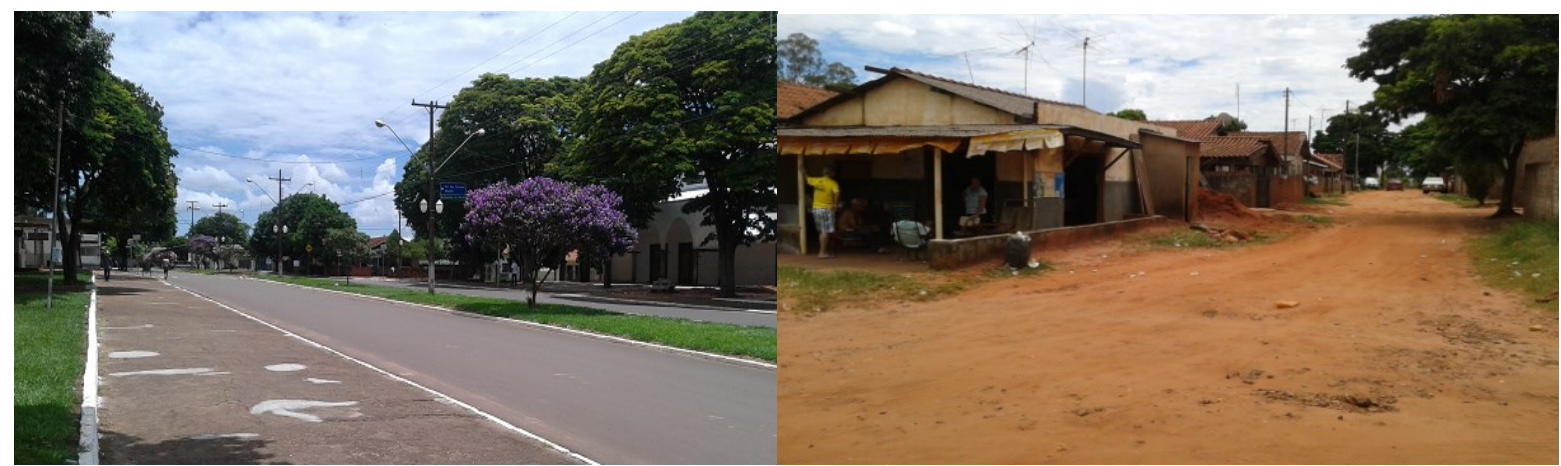

Fonte: RIBEIRO, 2016. 
Tais discrepâncias refletem a realidade espacial do país, que assiste ao crescimento de extensas periferias urbanas. Aponta Silva (2011) que, se outrora esse fenômeno fosse restrito às grandes cidades, atualmente, existe um processo semelhante que ocorre nas médias e também nas cidades pequenas, como no caso de Tamboara. A periferização se torna, no atual momento histórico, como uma expansão desordenada dos núcleos urbanos brasileiros e reflete a precariedade e 0 descaso de políticas públicas de infraestruturas para as cidades grandes, médias, e também demograficamente pequenas do nosso país.

Portanto, cabe mencionar que, se por um lado as agroindústrias sucroalcooleiras puderam proporcionar uma atração e relativa retenção populacional em municípios demograficamente pequenos do Noroeste Paranaense, por outro, elas não inibiram as contradições sociais e tampouco contribuíram no planejamento urbano de muitas cidades, como no caso em questão. É preciso que tenha, por parte do Estado, iniciativas que contemplem os municípios demograficamente pequenos do Noroeste do Paraná, para que os mesmos não reproduzam a miserabilidade social tão marcante historicamente na vida dos trabalhadores rurais volantes do Brasil. Para isso é importante levar em consideração a caracterização e o perfil desses trabalhadores migrantes, pois como poderá observar a seguir, eles denotam certa exclusão social, fruto da modernização conservadora e da reestruturação produtiva do capital em nosso país.

\section{Caracterização dos trabalhadores migrantes de Tamboara-PR}

Pelo fato de a força de trabalho migrante de Tamboara ser generalizadamente definitiva, não apenas homens migraram à cidade, mas também mulheres e crianças. Em alguns casos, o pai de família migrou e trouxe consigo sua esposa e filhos. Desde o início dos anos 2000, o município vem recebendo migrantes nordestinos para trabalhar, principalmente, na Usina COOPCANA. 0 Gráfico 01 apresenta a época em que esses trabalhadores migraram a Tamboara. 
Gráfico 1: Período de migração de trabalhadores a Tamboara - 2000 a 2013, por quantidade de migrantes.

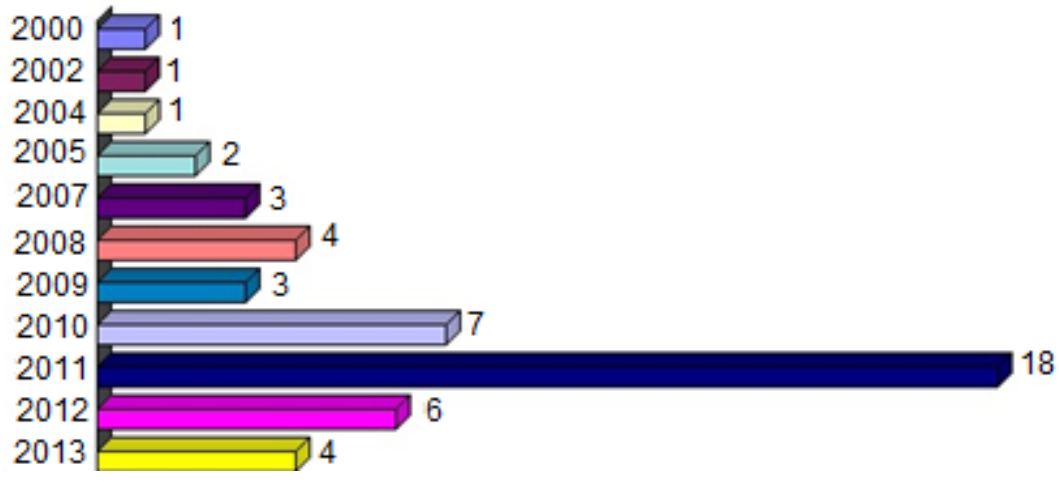

Fonte: RIBEIRO, 2016.

O período sinalizado pelo Gráfico 01 reflete principalmente o governo do então presidente Luis Inácio Lula da Silva, em que políticas públicas e financiamentos foram destinados ao ramo energético, aumentando, então, a produção do etanol, combustível que proporcionou novas frotas de veículos flex fuel. Uma das consequências dessas políticas públicas foi o aumento das culturas canavieiras e das atividades afins. A área nacional destinada ao plantio da cana-de-açúcar chegou a 4.879.841 hectares no ano de 2000, e em 2014 expandiu para 10.472169 hectares (RIBEIRO, 2016). Isso denota a expressividade do setor, que aumentou $214 \%$ aproximadamente sua área no período mencionado.

No que tange à colheita da cana-de-açúcar, importa mencionar que o setor tem vivenciado intensas transformações, principalmente com a mecanização do corte, o que tem causado mudanças na estrutura de trabalho. Estas têm se dinamizado pelo espaço nacional como um todo, alcançando o Noroeste Paranaense. Essa região tem conhecido uma escassez de oferta de força de trabalho local destinada a esta prática. Com isso, a demanda pela mobilidade de trabalhadores de outras regiões do país tem-se acentuado, a exemplo do que se percebe no município de Tamboara - PR. Assiste-se, desde então, uma intensa mobilidade da força de trabalho para o corte da cana-de-açúcar, sobretudo no Centro-Sul brasileiro, onde se concentra a produção e a lavoura canavieira do país e, mais especificamente, na região em estudo.

De acordo com a realidade estudada, nos anos de 2010, 2011 e 2012 ocorreram os maiores fluxos de mobilidade, culminando com o período em que a COOPCANA passou a investir mais na produção e na expansão de suas lavouras. Em 2010, de um total de cinquenta trabalhadores entrevistados (aproximadamente 16\% do universo), migraram sete trabalhadores nordestinos, e em 2011 e 2012 dezoito e seis, respectivamente. Esses dados concernem a 14\%, 36\% e 12\% do total. A grande maioria dessa mão de obra é oriunda do Estado do Ceará, como se pode observar na Tabela 1: dos cinquenta entrevistados, quarenta e dois são cearenses, totalizando aproximadamente $84 \%$ da 
realidade estudada. No que tange ao Estado da Bahia, seis trabalhadores, ou seja, $12 \%$ da amostra migraram ao município.

O percurso desses trabalhadores à cidade de destino é feito de "ônibus de linha", ou seja, de transporte interestadual, de modo que a Viação Gontijo foi a principal empresa a ser procurada para fazer o trajeto. Os trabalhadores oriundos dos Estados do Piauí, Ceará e Rio Grande do Norte optaram por ir até Salvador-BA, para depois virem ao Paraná. Essa empresa de transporte rodoviário faz um percurso de Salvador a Assunção - PY, sendo o principal meio de transporte de passageiros por acesso rodoviário ao Paraná. Embora sejam exacerbadas as despesas com o deslocamento, a maioria dos trabalhadores consegue emprego em Tamboara e arca com os custos, compensando o gasto, diante da perspectiva de conseguirem uma melhor qualidade de vida para suas famílias.

Tabela 01: Estados de origem dos trabalhadores migrantes de Tamboara, quantidade citada e frequência- 2000 a 2013.

\begin{tabular}{l|c|c}
\hline Estado de origem & Nb.cit & Fréq. \\
\hline Ceará & 42 & $84 \%$ \\
Bahia & 6 & $12 \%$ \\
Piauí & 1 & $2 \%$ \\
Rio Grande do Norte & 1 & $2 \%$ \\
\hline Total Obs. & $\mathbf{5 0}$ & $\mathbf{1 0 0} \%$ \\
\hline
\end{tabular}

Fonte: RIBEIRO, 2016.

O município de Jardim, no Estado do Ceara, é a localidade de origem da maioria da força de trabalho migrante de Tamboara (Gráfico 02). De um total de cinquenta trabalhadores, vinte e oito são oriundos desta cidade, o que corresponde a $56 \%$ da realidade estudada. O município de Barbalha é 0 local de origem de onze trabalhadores, ou seja, $22 \%$ do estudo de campo. Os municípios de AraripeCE e Irecê-BA foram origem de dois e quatro trabalhadores, respectivamente, correspondendo a $4 \% \mathrm{e}$ $8 \%$ dos migrantes. As demais localidades somam $10 \%$ da amostra. 
Gráfico 02: Municípios de origem dos trabalhadores migrantes, quantidade citada- 2000 a 2013.

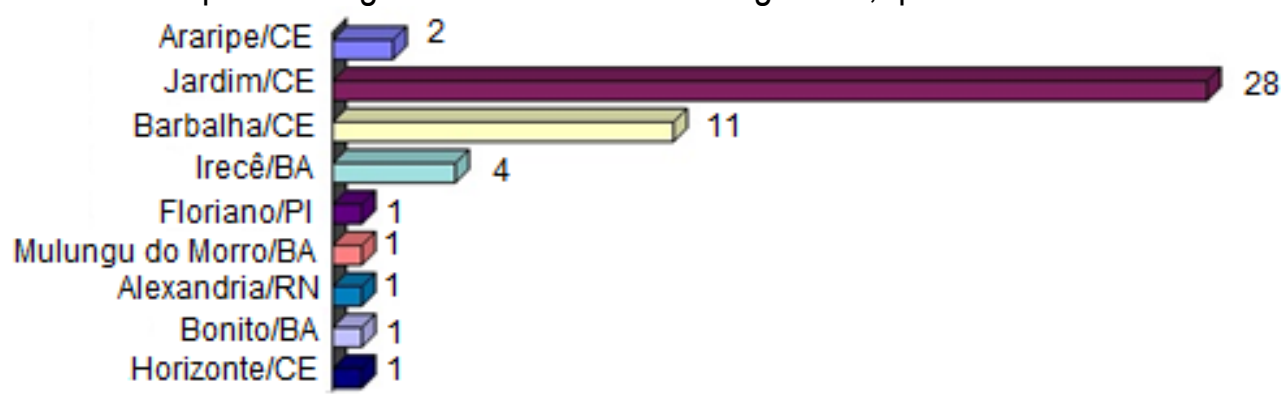

Fonte: RIBEIRO, 2016.

Observou-se na pesquisa que o número de habitantes dos municípios de origem dos trabalhadores é superior à população da localidade de destino. Tamboara possuía, de acordo com 0 censo demográfico de 2010, aproximadamente 4.664 habitantes. O que se assiste atualmente na economia sucroalcooleira é uma migração diferenciada do padrão comum. No universo da atividade canavieira do presente estudo, o trabalhador normalmente migra com destino a uma cidade demograficamente menor, contrariando a maioria dos estudos de mobilidade da força de trabalho. 0 que diferencia Tamboara dos municípios de origem, além de uma melhor infraestrutura básica, é o Índice de Desenvolvimento Humano (IDH 1 ), que se aproxima de 0,75, considerado alto pelo Programa das Nações Unidas para o Desenvolvimento.

Dos municípios de origem mencionados, o município de Floriano - PI foi o único que apresentou, em 2010, um IDH considerado alto, 0,7. Já Araripe - CE, Mulungu do Morro - BA e Bonito BA, com IDH entre 0,500 a 0,599, são considerados baixos. As demais localidades com IDH entre 0,600 a 0,699 são consideradas médias (Tabela 02).

1 O IDH tem por objetivo medir a expectativa de vida ao nascer, a educação, o PIB per capta e outros indicadores do padrão de vida. Quanto mais próximo de 1, melhor o país ou o município, melhores Investimentos em saúde e em educação e segurança e menor a desigualdade social e concentração de renda, dentre outros. 
Tabela 02: Municípios de origem dos trabalhadores migrantes, população e IDH- 2010.

\begin{tabular}{l|c|c}
\hline Municípios de origem & População (em habitantes) & IDH \\
\hline Araripe-CE & 20.689 & 0,584 \\
Jardim-CE & 26.697 & 0,614 \\
Barbalha-CE & 55.323 & 0,683 \\
Irecê-BA & 66.181 & 0,691 \\
Floriano-PI & 57.690 & 0,7 \\
Mulungu do Morro-BA & 12.270 & 0,566 \\
Alexandria-RN & 13.507 & 0,606 \\
Bonito-BA & 14.834 & 0,561 \\
Horizonte-CE & 55.187 & 0,679 \\
\hline
\end{tabular}

Fonte: RIBEIRO, 2016.

É preciso ressaltar, também, que $0 \mathrm{IDH}$ não explica toda a problemática que solapa determinadas regiões do país. A questão étnico-social ainda é um dilema na sociedade brasileira. Embora atualmente tenha ocorrido um avanço socioeconômico e melhorias de vida da população negra, com acesso aos serviços e às cotas para o ingresso ao ensino superior dentre outros, esses avanços não contemplam a grande maioria. Por mais que os jovens negros, hoje, tenham mais oportunidades que os mais velhos, o abismo racial no Brasil ainda não chegou ao fim. Os serviços no corte manual da cana-de-açúcar refletem essa questão. Dentre aqueles que migraram para Tamboara, $84 \%$ se consideraram da etnia parda e $14 \%$ preta. Esses dois grupos étnicos compreendem $98 \%$ da realidade estudada (Tabela 03).

Tabela 03: Grupos étnicos dos trabalhadores migrantes de Tamboara, quantidade citada e frequência.

\begin{tabular}{l|c|c}
\hline \multicolumn{1}{c|}{ Etnia } & Nb. cit. & Fréq. \\
\hline Preta & 7 & $14 \%$ \\
Branca & 1 & $2 \%$ \\
Indígena & 0 & $0 \%$ \\
Parda & 42 & $84 \%$ \\
\hline Total Obs. & $\mathbf{5 0}$ & $\mathbf{1 0 0} \%$ \\
\hline
\end{tabular}

Fonte: RIBEIRO, 2016.

Considerando a realidade escolar, percebe-se que os baixos índices permeiam essa categoria étnica e essa força de trabalho. Embora os entrevistados, quando frequentaram as escolas, tenham realizado estudos pautados na antiga nomenclatura $\left(1^{\circ}\right.$ e $2^{\circ}$ Graus), vale ressaltar que, de acordo com o Gráfico 3, vinte e um trabalhadores, $42 \%$ do grupo estudado, não concluíram o que hoje corresponde 
aos anos iniciais do ensino fundamental, ou seja, têm menos de cinco anos de estudo escolar. Apenas cinco trabalhadores, ou seja, $10 \%$ dos entrevistados, terminaram o atual ensino médio.

Gráfico 03: Nível escolar dos cortadores de cana migrantes de Tamboara, por quantidade citada.

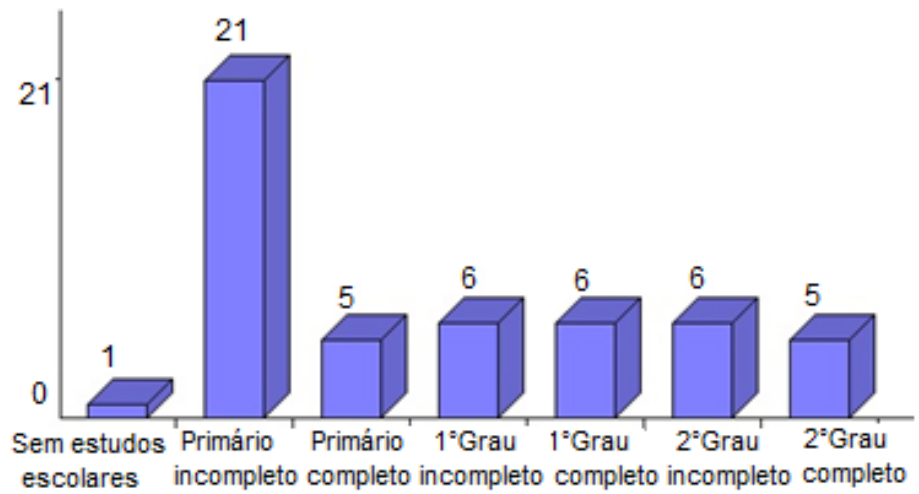

Fonte: RIBEIRO, 2016

Os baixos índices escolares refletem diretamente no mercado de trabalho. Os serviços no meio rural empregam quase que exclusivamente trabalhadores com baixa escolaridade, e os que terminam o atual Ensino Médio dispõem de novas e melhores oportunidades nas unidades de produção, inclusive para uma melhor qualificação, a exemplo de cursos técnicos. Embora a grande maioria dos cortadores migrantes esteja inserido no corte da lavoura, o setor oferece cursos profissionalizantes para os trabalhadores migrarem a outros postos de trabalho, como motoristas, fiscais de produção, no que tange à mecânica e à manutenção, dentre outros, proporcionando, então, uma relativa mobilidade social dessa força de trabalho.

É preciso que fique claro que nem sempre a maior qualificação da força de trabalho proporciona soluções para a mobilidade social ou o aumento da renda. Se os trabalhadores, sejam eles do setor canavieiro ou de outros ramos das atividades agrícolas, melhorassem o nível de qualificação, um dos resultados seria uma intensa concorrência entre eles, com provável diminuição dos salários. Nesse sentido, aponta Singer (1999) que:

a qualificação maior interessa ao trabalhador individual para obter uma vantagem na luta por empregos, mas só traria vantagens aos trabalhadores em conjunto se fosse possível negociar escalas de salário que remunerassem melhor os de mais qualificação, sem reduzir o ganho dos menos qualificados (SINGER, 1999: 120).

Para que ocorra de fato a mobilidade social, é necessário garantir ao trabalhador, seja ele cortador ou trabalhador interno, não apenas a qualificação, mas também direitos trabalhistas, 
assistências hospitalares, além de investir na infraestrutura urbana a fim de possibilitar uma melhor qualidade de vida e inserção efetiva na cidade.

O Gráfico 04, a seguir, apresenta as principais atividades rurais atualmente exercidas pelos trabalhadores estudados nesta pesquisa desenvolvida em Tamboara. Percebe-se que a grande maioria, quarenta e quatro trabalhadores, ou seja, $88 \%$ dos entrevistados, trabalham no corte da canade-açúcar. A atividade de bituqueiro (a), por exemplo, é aquela responsável pela retirada dos restos de cana que sobram no solo após o corte. Esses serviços são feitos principalmente por mulheres e, no caso pesquisado, as duas pessoas que realizam essa atividade, conforme sinaliza 0 Gráfico 4, são mulheres e da faixa etária dos 40 aos 50 anos.

Gráfico 04: Atividade profissional dos migrantes de Tamboara, por quantidade citada.

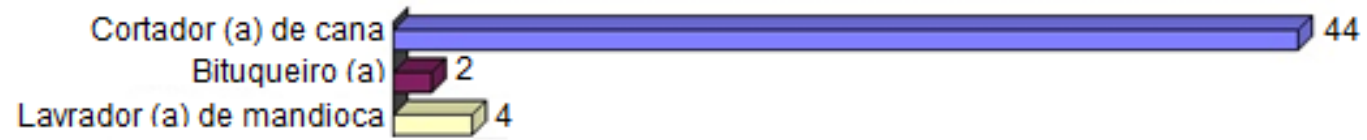

Fonte: RIBEIRO, 2016

Os lavradores de mandioca são trabalhadores que chegaram a Tamboara com menos de 18 anos. Estes seguiram seus pais, parentes ou amigos. Como o setor canavieiro não emprega menores no corte da cana, eles se inseriram nas atividades de plantio e colheita da mandioca, que também se desenvolve no município. Quando foi realizada a pesquisa de campo, nos anos de 2013/14, esses trabalhadores completaram 18 anos e já planejavam trabalhar no setor sucroalcooleiro por ofertar mais oportunidades, melhores salários e registros na carteira de trabalho. Geralmente, os serviços na lavoura de mandioca são temporários e predominam salários inferiores ao setor energético.

Por mais que o trabalho manual no corte da cana-de-açúcar seja exaustivo e difícil, percebe-se que a idade desses trabalhadores varia, principalmente, entre os 18 e os 50 anos. No que tange à realidade estudada, 23 trabalhadores estão na faixa etária dos 21 a 30 anos e contabilizam $46 \%$ da totalidade entrevistada, conforme apresenta a Tabela 4. A faixa etária de 31 a 40 anos compreende $32 \%$ dessa força de trabalho, enquanto jovens de 18 a 20 anos somam $12 \%$, e adultos dos 41 a 50 anos e mais que 50 totalizam apenas $6 \%$ e $4 \%$, respectivamente. 
Tabela 04: Idade dos trabalhadores migrantes de Tamboara por faixa etária, quantidade citada e frequência.

\begin{tabular}{l|c|c}
\hline Faixa Etaria & Nb. cit. & Fréq. \\
\hline 18 a 20 & 6 & $12 \%$ \\
21 a 30 & 23 & $46 \%$ \\
31 a 40 & 16 & $32 \%$ \\
41 a 50 & 3 & $6 \%$ \\
mais que 50 & 2 & $4 \%$ \\
\hline TOTAL Obs. & $\mathbf{5 0}$ & $\mathbf{1 0 0} \%$ \\
\hline
\end{tabular}

Fonte: RIBEIRO, 2016.

Embora predominem homens nos serviços de corte da cana-de-açúcar, um número significativo de mulheres também compõe essa força de trabalho. A força de trabalho feminina empregada no corte da gramínea compreende 11 mulheres do total entrevistado, que somam $22 \%$ da realidade estudada, de acordo com 0 Gráfico 05. Apenas duas mulheres entrevistadas migraram para acompanhar familiares e se casaram em Tamboara com paranaenses. As restantes foram com 0 propósito de acompanhar os maridos. Importa mencionar que a saída de mulheres do âmbito familiar de origem prejudica a reprodução dos saberes das práticas agrícolas, bem explanada por Mendonça (2012). Os saberes e as práticas agrícolas são importantes para o fortalecimento do campesinato e para inibir a mobilidade forçada de camponeses e camponesas no espaço geográfico brasileiro.

Gráfico 05: Gênero da força de trabalho migrante de Tamboara, por quantidade citada.

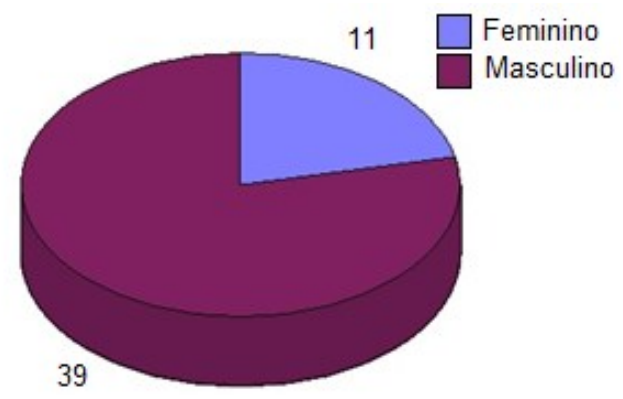

Fonte: RIBEIRO, 2016.

A grande maioria dessa força de trabalho é composta por solteiros (Gráfico 06). Dos cinquenta entrevistados, trinta e seis eram solteiros e quatorze casados. Isso compreende, respectivamente, $72 \%$ e $28 \%$ do estudo de campo. Esse fato se dá em virtude de a grande maioria dessa força de trabalho compreender jovens adultos dos 18 aos 30 anos. Tanto Petersen (1965) quanto Beaujeu-Garnier 
(1971), estudiosos da questão populacional, ressaltam que os jovens adultos, especialmente os solteiros, são mais propícios a migrarem, pois buscam mais oportunidades e estão mais aptos a se adaptar às mais variadas diversidades no mundo do trabalho. Esse fenômeno reflete na atividade canavieira, principalmente no que diz respeito ao corte da gramínea, um serviço de extrema exaustão que os jovens estão mais preparados para suportar.

Gráfico 06: Estado civil dos trabalhadores migrantes, por quantidade citada.

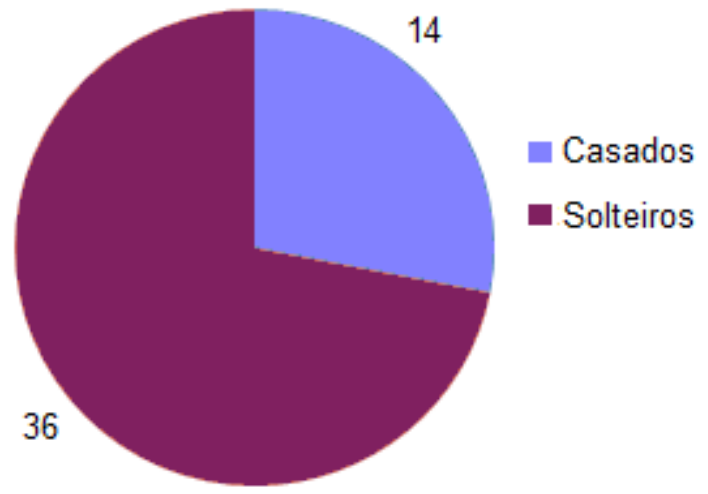

Fonte: RIBEIRO, 2016.

Os trabalhadores migrantes adquiriram, no núcleo urbano, moradia própria, por meio de financiamento, proporcionado pelo emprego com registro em carteira, ou alugaram-na. Existe aqueles que migraram e, no momento da pesquisa de campo, moravam com amigos ou parentes. Os que conseguiram casa própria somam oito trabalhadores, ou seja, 16\%. A maioria, trinta e sete trabalhadores, que correspondem a $74 \%$ do estudo, moram em casas alugadas, e apenas cinco vivem em casas de amigos ou parentes (Gráfico 07).

Gráfico 07: Situação de moradia dos trabalhadores migrantes, quantidade citada.

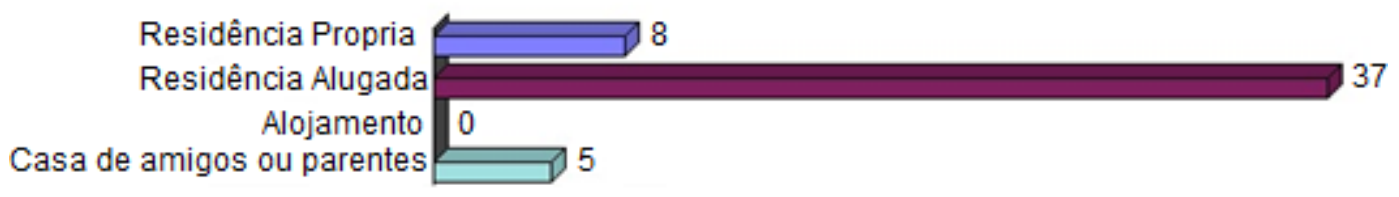

Fonte: RIBEIRO, 2016.

Se atualmente essa força de trabalho vive no meio urbano, a quase totalidade viveu a maior parte de sua vida na zona rural. Dos cinquenta entrevistados, quarenta e sete trabalhadores moraram a maior parte do tempo no campo, e apenas três viveram na cidade quando estavam em seus municípios de origem (Gráfico 08). Isso denota que são trabalhadores de origem rural, e essa migração de 
grandes percursos no território brasileiro reflete o empobrecimento do campesinato e a expropriação e concentração da terra. Esses fenômenos contraditórios foram fatores cruciais para a consolidação dessa força de trabalho no setor energético.

Gráfico 08: Origem dos trabalhadores migrantes das zonas rural e urbana, quantidade citada.

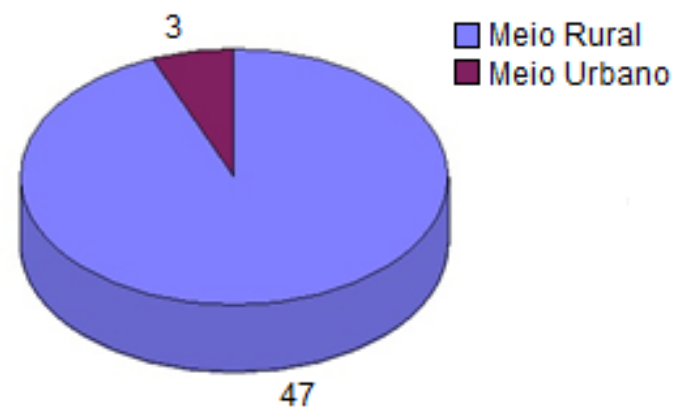

Fonte: RIBEIRO, 2016.

Essa força de trabalho sujeitou-se às diversas transformações que se desencadearam historicamente no meio rural do país. De acordo com os estudos populacionais de Beaujeu-Garnier (1971), o povoamento e a mobilidade rural se processam em três etapas: a primeira se dá em função da conquista progressiva e desenvolvimento da terra; a segunda é uma retirada, provocada por certos problemas, dentre outras circunstâncias econômicas e políticas; e a terceira uma reocupação.

Essas etapas refletem a realidade dos trabalhadores rurais brasileiros, especialmente os nordestinos. Estes saíram de um campo pobre do nordeste e passaram pela cidade moderna, progressista e industrializada, seja nas grandes cidades nordestinas, ou de outras regiões do Brasil. Pelo fato de não se inserirem e adaptarem-se aos serviços modernos que necessitam de certos níveis de escolarização e tecnificação, voltaram a um campo industrializado e comandado pelo urbano. Por mais que os trabalhadores migrantes de Tamboara vivam no meio urbano, estes veem no campo as poucas possibilidades de conseguirem trabalho para a sobrevivência e relativa mobilidade social.

A grande instabilidade de uma parcela significativa da força de trabalho nordestina, sempre pronta para migrar a outras localidades, denota problemas de organização interna nos municípios de origem, que assistem sua população trabalhadora diminuir, seus campos se esvaziarem e o comércio e a economia local se enfraquecerem. Já a região de destino é contemplada com esses trabalhadores, em que determinadas atividades econômicas adquirem força de trabalho para aumentar a produção, a cidade se expande e a população cresce, aumentando a circulação de capital no comércio local.

Os municípios de origem dos trabalhadores migrantes de Tamboara entrevistados nesta pesquisa compreendem, na maior parte, localidades estagnadas demograficamente, como pode-se 
observar na Tabela 05. No decorrer de aproximadamente vinte anos, os municípios de Araripe, Bonito e Jardim, tiveram baixo crescimento populacional. Já Alexandria e Mulungu do Moro, mesmo que timidamente, presenciaram uma diminuição demográfica. Os municípios de Barbalha, Floriano, Irecê e principalmente Horizonte tiveram um relativo aumento populacional. Esse fato denota que, embora ocorresse um relativo crescimento demográfico, 0 desenvolvimento econômico e social não contemplou a grande maioria de suas respectivas populações. Em se tratando do Estado do Ceará, o município de Horizonte presenciou um aumento expressivo de sua população, de 18.283 habitantes em 1991 para 55.187 em 2010, devido a essa localidade ser próxima da capital, Fortaleza, e compreender a Região Metropolitana cearense. O crescimento econômico vivenciado pela capital refletiu nas cidades ao redor.

Tabela 05: Evolução populacional dos municípios de origem dos trabalhadores imigrantes de Tamboara.

\begin{tabular}{l|c|c|c|c|c}
\hline \multicolumn{1}{c|}{ Municípios } & $\mathbf{1 9 9 1}$ & $\mathbf{1 9 9 6}$ & $\mathbf{2 0 0 0}$ & $\mathbf{2 0 0 7}$ & $\mathbf{2 0 1 0}$ \\
\hline Araripe-CE & 17.409 & 17.584 & 19.606 & 21.214 & 20.685 \\
Alexandria-RN & 14.580 & 13.577 & 13.772 & 13.729 & 13.507 \\
Barbalha-CE & 38.430 & 43.187 & 47.031 & 50.386 & 55.323 \\
Bonito-BA & 11.085 & 14.315 & 12.902 & 13.678 & 14.834 \\
Floriano-PI & 51.494 & 51.970 & 54.591 & 56.090 & 57.690 \\
Horizonte-CE & 18.283 & 25.378 & 33.790 & 48.660 & 55.187 \\
Irecê-BA & 50.908 & 51.956 & 57.436 & 62.676 & 66.181 \\
Jardim-CE & 23.964 & 24.971 & 26.414 & 25.853 & 26.688 \\
Mulungu do Morro-BA & 13.741 & 14.547 & 15.119 & 13.755 & 12.249 \\
\hline
\end{tabular}

Fonte: RIBEIRO, 2016.

Embora a região nordestina tenha, nos últimos anos, vivenciado um movimento populacional de retorno, esse fluxo está direcionado quase que exclusivamente às grandes regiões metropolitanas. Muitas localidades, especialmente do interior semiárido, convivem ainda com a emigração, sobretudo de jovens adultos (RIBEIRO, 2016). Essa emigração se dá em função do descontentamento desencadeado pela infraestutura precária, e isso tem ocasionado a queda dos padrões de qualidade de vida.

A queda nos padrões de qualidade de vida gera incertezas e acarreta o movimento populacional emigratório (PETERSEN, 1965). O Gráfico 09 apresenta as motivações que levaram os trabalhadores rurais migrantes de Tamboara a deixarem o Nordeste. Dos entrevistados, $60 \%$ migraram em busca de emprego. Já $22 \%$ buscaram melhores condições de vida e 18\% acompanharam familiares. 
Gráfico 09: Motivações que levaram à emigração, por quantidade citada.

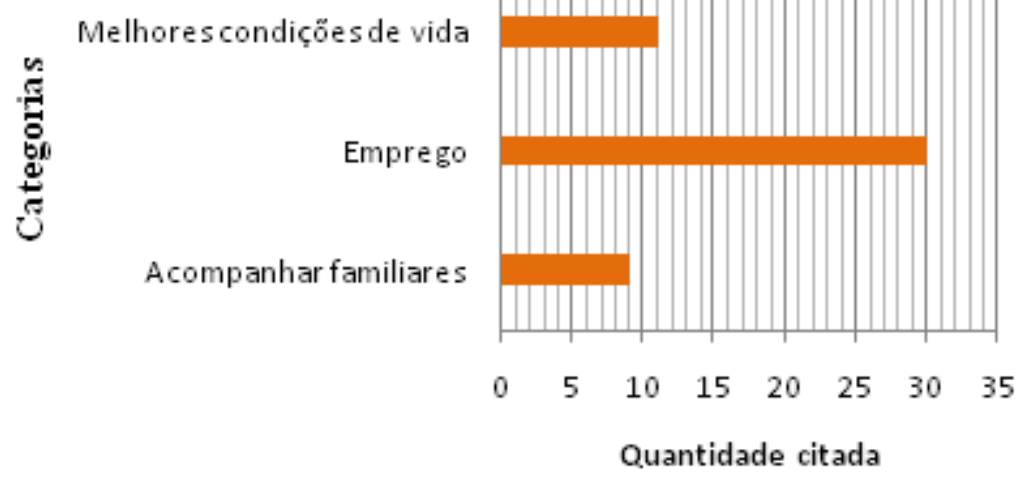

Fonte: RIBEIRO, 2016.

É a busca pelo direito à qualidade de vida e à mobilidade social ascendente tão desejada, centrada nas relações de trabalho, historicamente presente na família nordestina que figura como principal motivo. Muitos trabalhadores relataram que recebiam apenas duzentos reais mensalmente com as atividades temporárias exercidas no campo ou no meio rural do município de origem. No Paraná, mesmo estando empregados em uma atividade exaustiva em que predominam trabalhadores de baixa escolarização, o cortador(a) de cana-de-açúcar pode ganhar até três salários mínimos nos anos de 2013/14, como mostra o Gráfico 10. Foram nove trabalhadores, ou seja, $18 \%$ dos entrevistados que recebiam até três salários mínimos no corte da gramínea. Vale ressaltar que o pagamento feito pelo setor sucroalcooleiro é dado pela produtividade no eito. Quanto mais cana-deaçúcar o trabalhador cortar, mais ele ganhará. Os mais jovens, sobretudo dos 18 aos 35 anos, podem resistir mais ao cansaço físico e trabalhar nos terrenos mais difíceis, onde a produtividade é maior, proporcionando, então, melhores salários.

Os trabalhadores que recebiam dois salários mínimos compreendem $52 \%$, mais da metade dos entrevistados, e quinze trabalhadores, correspondente $28 \%$, recebiam 1 salário mínimo. Neste grupo também estão aqueles que trabalham na lavoura de mandioca, cujos salários geralmente são inferiores. Apenas uma trabalhadora relatou que recebia $1 / 2$ salário, pois fazia serviço de "bituqueira", recolhendo os restos de cana que ficavam no solo. Essa atividade é temporária, realizada quase que exclusivamente após a safra e geralmente predominam menores salários e tempos de serviço. Importa mencionar que os primeiros, que exercem função na COOPCANA, possuem direitos trabalhistas assegurados devido ao registro em carteira, contudo, a última (bituqueira) não possui essas condições, pois trabalha de forma autônoma, recolhendo restos da cana-de-açúcar após a colheita, não estando sujeita a horários ou condições que a empresa impõe. 
Gráfico 10: Renda aproximada obtida no Paraná pelos nordestinos.

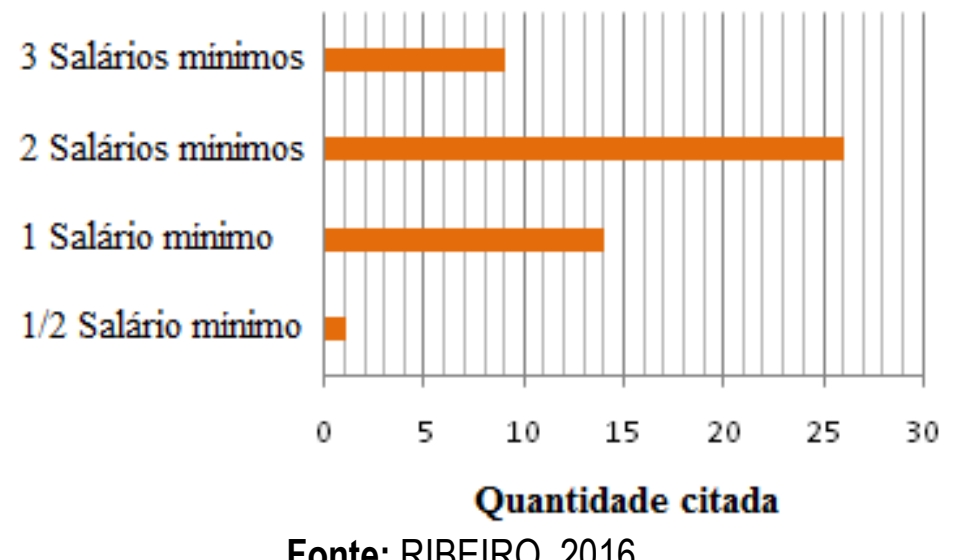

Fonte: RIBEIRO, 2016.

A renda adquirida no Paraná proporciona a essa força de trabalho um melhor nível de vida dentro de seus padrões tradicionais. Acredita-se, nesse caso, que o salário ganho na localidade de destino possibilita ao trabalhador um melhor nível de vida dentro de suas possibilidades de consumo e de seu padrão tradicional. As conquistas importantes que a força de trabalho migrante adquiriu em Tamboara remetem principalmente no que diz respeito ao emprego e à casa própria. Dos cinquenta entrevistados, $44 \%$ relataram que a principal conquista foi o emprego formal e $22 \%$, o equivalente a onze trabalhadores, afirmaram a casa própria como a maior conquista. Dentres esses, estão filhos e esposas de trabalhadores que afirmaram a mesma resposta, pois como foi observado no Gráfico 07 oito famílias adquiriram casa própria.

Tabela 06: Conquistas importantes dos migrantes nordestinos no Paraná, quantidade citada e frequência.

\begin{tabular}{l|c|c}
\hline \multicolumn{1}{c|}{ Categorias } & Nb. Cit & Fréq. \\
& & \\
\hline Emprego & 22 & $44 \%$ \\
Amigos e família & 8 & $16 \%$ \\
Casa própria & 11 & $22 \%$ \\
Bens de consumo & 9 & $18 \%$ \\
\hline Total Obs. & $\mathbf{5 0}$ & $\mathbf{1 0 0 \%}$ \\
\hline
\end{tabular}

Fonte: RIBEIRO, 2016.

A Tabela anterior aponta que $16 \%$ dos trabalhadores tiveram amigos e familiares na localidade de destino como conquistas mais importantes. Pelo fato de ser uma migração de cunho definitivo, alguns trabalhadores se casaram em Tamboara e constituíram famílias, novas amizades e criaram novos laços afetivos. Já os bens de consumo foram relatados por $18 \%$ dos entrevistados, sendo 
motocicletas e automóveis os principais bens adquiridos, impossíveis de serem conquistados outrora na região de origem.

A emigração definitiva a Tamboara, a conquista do emprego formal, a residência própria, além dos novos laços familiares e o consumo proporcionaram a quase totalidade desses trabalhadores uma ascensão econômica e relativa mobilidade social, além de uma inovação no seu padrão de vida por meio do consumo. Para quarenta e oito trabalhadores, ou seja, $96 \%$ conquistaram a ascensão econômica e mobilidade social tão desejada (Gráfico 11). Apenas dois trabalhadores, isto é, 4\% afirmaram que não tiveram uma ascensão esperada. Para estes, o custo de vida, a dificuldade de adaptação à região, sobretudo em épocas de inverno, dificultam a vida. São trabalhadores recémchegados a Tamboara, e por mais que seja difícil a adaptação, eles pretendem continuar no Paraná, pois a precariedade da região de origem os impede de retornar.

Gráfico 11: Trabalhadores nordestinos que tiveram ascensão econômica no Paraná (quantidade citada).

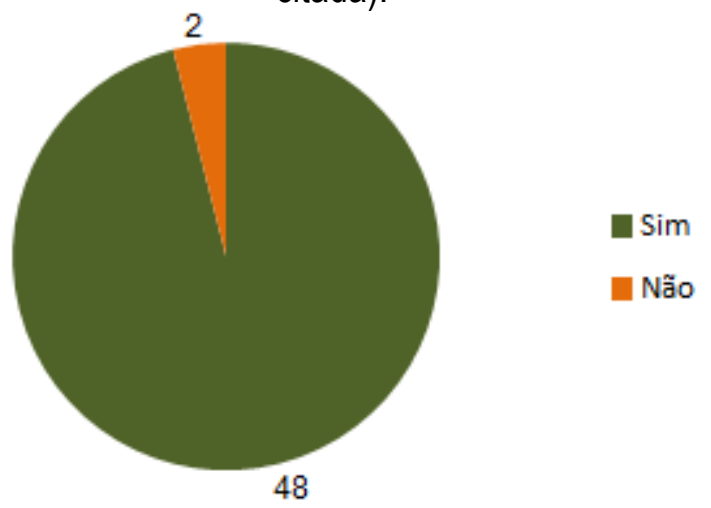

Fonte: RIBEIRO, 2016.

A ascensão econômica desses trabalhadores é importante para eles, bem como para 0 município de Tamboara. A possibilidade do aumento do poder de consumo por parte dessa força de trabalho proporciona um movimento na economia local, contribuindo com o desenvolvimento e refletindo no processo de produção do espaço geográfico da localidade em questão. Contudo, vale ressaltar, também, que a classe trabalhadora, seja ela operária ou camponesa, não pode ser marginalizada no âmbito do mercado de consumo interno, impedindo-a de participar do consumo de certos produtos cruciais para a sua reprodução. Em suma, como reitera Singer (1977), o capital, por meio do mercado, cria e recria as condições em que se dá a reprodução da força de trabalho. 0 consumo, então, acaba sendo o estímulo para que os membros da população economicamente ativa alienem a sua capacidade de trabalho às relações capitalistas. 


\section{Considerações}

O modelo econômico brasileiro, pautado sobretudo na economia agroexportadora, tem provocado no Nordeste uma relativa ascensão da pobreza no campo e nas cidades. Com o esvaziamento da zona rural, o meio urbano cresceu desordenadamente, resultando uma série de aspectos negativos na região, dentre eles, como ressalta Andrade (1988), o desrrespeito ao meio ambiente, a destruição dos recursos naturais e a desvalorização da cultura nacional. Esse crescimento desordenado dos núcleos urbanos provoca queda nos padrões de qualidade de vida da população, subretudo àquela oriunda do meio rural, e desencadeia o movimento migracional.

Essa necessidade de mudança, seja ela temporária ou permanente, é reflexo da organização interna do país. Se por um lado esses migrantes contribuem com a evolução econômica de determinadas regiões, por outro, podem acarretar diversas crises no âmbito do desenvolvimento local das cidades de origem. Por isso um olhar atento às novas alternativas e possibilidades de desenvolvimento de economias locais nos municípios de origem, a fim de desenvolver um dispositivo de retenção de população que iniba essa instabilidade da força de trabalho e a mobilidade forçada, gerando emprego, renda e pertencimento aos locais de origem (RIBEIRO, 2016).

A agropecuária no Brasil apresenta estas duas faces: por um lado o agronegócio, com uma expressiva produtividade que o coloca como um dos mais importantes e competitivos do mundo, apesar das barreiras nos principais mercados internacionais, e de outro a questão agrária amplamente debatida no âmbito acadêmico e político em que milhares de trabalhadores rurais se encontram sem emprego e terra, deixando-os sem condições de prover a própria subsistência. Essa contradição vem reproduzindo os fluxos populacionais no território brasileiro, a exemplo do que foi apresentado nessa pesquisa.

No entanto, percebe-se que os avanços na agricultura brasileira pautados no emprego de tecnologias avançadas graças ao desenvolvimento científico não foram acompanhados de melhorias das condições dos trabalhadores. Como observa Silva (2008), existe uma relação entre os avanços científicos e os lucros de um lado, e de outro a diminuição do preço da força de trabalho. Isso acarreta na precariedade das condições de trabalho e dos níveis de exploração, além de gerar os fluxos populacionais. Concomitante a esses fenômenos tem também questão da moradia, em que milhões de brasileiros vivem ainda em domicílios sem infraestrutura adequada, sem rede de esgoto, água encanada, dentre outros serviços. Essa pesquisa identificou que as condições precárias de infraestrutura nos municípios de origem dos migrantes estudados foram algumas das motivações que os fizeram migrar ao Paraná. 
Essas contradições sociais refletem a atual organização interna do país, e denotam os novos papéis e significados do Estado para com o capital nacional e estrangeiro e com a sociedade como um todo. Dentre os principais objetivos do Estado, estão ajudar e incentivar a economia moderna, materializada em grandes empresas capitalistas altamente tecnificadas do circuito superior da economia, em detrimento dos serviços públicos de âmbito social. Com isso, a reestruturação produtiva do capital, processa-se, por parte das grandes firmas, em função das concessões e apoio direto do Estado, bem observado por Miliband (1972):

A empresa capitalista depende em grau cada vez maior das concessões e do apoio direto do Estado, e só pode preservar seu caráter privado à base desse apoio público. A intervenção estatal na vida econômica significa de fato, em sentido amplo, uma intervenção destinada a ajudar a empresa capitalista. A noção de "Estado do bem estar" não teve em outra esfera uma significação mais preciosa e oportuna do que aqui: não existem candidatos ao auxílio público mais persistentes do que os orgulhosos gigantes do sistema de empresa privada (MILIBAND, 1972: 100).

A discrepância entre as regiões brasileiras e os dados sociais bem como a caracterização social dos trabalhadores rurais estudados estão intimamente articuladas aos novos papéis e às novas relações do Estado nacional que, no processo de reestruturação do capital, incentiva as grandes fábricas globais em detrimento das conquistas trabalhistas e dos serviços públicos, dentre outros investimentos sociais. Novos olhares e novas alternativas de desenvolvimento local pautadas em empresas populares, sociais e solidárias de autogestão poderão proporcionar elementos cruciais para o debate que almeja o processo de erradicação de toda uma miserabilidade social que solapa há tempo a população nordestina do Brasil.

\section{Referências}

ANDRADE, Manuel Correia de. O Nordeste e a questão regional. São Paulo: Ática, 1988. BEAUJEU-GARNIER, Jacqueline. Geografia de população. $2^{a}$ ed. São Paulo: Editora Nacional, 1971. CARVALHO, José Rodrigues de. Cancioneiro do Norte. $2^{a}$ Ed. São Paulo: Typographia da Livraria Nacional, 1928.

GHIZZO, Márcio Roberto. A mobilidade do consumo e a produção do espaço no aglomerado urbano de Maringá-PR. Tese (Doutorado em Geografia). Programa de Pós Graduação em Geografia. Universidade Estadual de Maringá. Maringá, 2012.

HARVEY, David. A condição pós-moderna. São Paulo: Edições Loyola, 1993.

IANNI, Octavio. A luta pela terra: história social da terra e a luta pela terra numa área da Amazônia. Petrópolis: Vozes, 1978.

IANNI, Octavio. A era do globalismo. 3a Ed. Rio de Janeiro: Civilização Brasileira, 1997.

IBGE. Censos demográficos 1991, 2000, 2010. Disponível em : <www.ibge.gov.br>. 
IPARDES. Caderno estatístico- Município de Tamboara, 2013. Disponível em: <www.ipardes.gov.br>. LIMA, Maria das Graças de. Contribuições aos procedimentos de pesquisa em geografia humana: questionários e entrevistas para levantamento de informações. In: FERREIRA, M. E. C; ROCHA, M.M; ENDLICH, A. M. Apontamentos geográficos I. Maringá: UEM/ PGE, 2011, 153p.

MENDONÇA, Marcelo Rodrigues. Experiências agroecológicas no cerrado em Goiás: o cultivo de sementes crioulas como estratégia de reprodução camponesa. In: MENDONÇA, Marcelo Rodrigues (org). Agroecologia: prática e saberes. 2a Ed. Catalão: Gráfica Modelo, 2012.

MILIBAND, Ralph. O Estado na sociedade capitalista. Rio de Janeiro. Zahar. 1972.

PERROUX, François. A Economia do século XX. Porto: Herder, 1967.

PETERSEN, William. Population. New York: The Macmillan Company, 1965.

PRADO JR, Caio. Formação do Brasil Contemporâneo. 10ª Ed. São Paulo: Editora Brasiliense. 1970.

RIBEIRO, Joaquim. Folclore do açúcar. Rio de Janeiro: Campanha de Defesa do Folclore Brasileiro, 1977.

RIBEIRO, Vitor Hugo et al. Transformações da paisagem rural da microrregião de Paranavaí-PR e a expansão da cana-de-açúcar nos Municípios de Tamboara e Itaúna do Sul de 1970-2012. Revista Percurso. Maringá. vol. 5, $n^{\circ}$ 1. p. 55-86, 2013.

RIBEIRO, Vitor Hugo. São Tomé-PR: um município “ilhado" pelo canavial. Revista Pegada Eletrônica. Presidente Prudente. vol. 14, n.1. p. 208-232, 2013.

RIBEIRO, Vitor Hugo. Os "cassacos" migrantes de Tamboara - PR: a mobilidade forçada e as resistências no processo de produção do espaço geográfico de Jardim - CE. Tese (Doutorado em Geografia). Programa de Pós Graduação em Geografia. Universidade Estadual de Maringá. Maringá, 2016.

SILVA, José Borzacchiello da. Ceará: os movimentos migratórios- o homem sem terra e a marginalidade urbana. Geonordeste. Ano 1, n². p. 46-51, 1984.

SILVA, Maria Aparecida de Moraes. Trabalhadores rurais: a negação dos direitos. $32^{\circ}$ Encontro Anual da Associação Nacional de Pós-Graduação e Pesquisa em Ciências Sociais. ANPOCS, Caxambu, 2008.

SINGER, Paul. Economia política do trabalho: elementos para uma análise histórico-estrutural do emprego e da força de trabalho no desenvolvimento capitalista. São Paulo: Hucitec. 1977.

SINGER, Paul. Globalização e desemprego: diagnóstico e alternativas. 3a Ed. São Paulo: Contexto. 1999.

(Recebido em 15-01-2017; Aceito em: 26-01-2017) 